\title{
The growth poles and the lagging regions of Romania - a county level approach for 2015 -
}

\author{
Vasile Alecsandru STRAT \\ The Bucharest University of Economic Studies, Bucharest, Romania \\ vasile.strat@csie.ase.ro \\ Cristian STEFAN \\ Bucharest, Romania \\ cristianstefan1984@yahoo.com
}

\begin{abstract}
In nowadays European context the challenges started from the severe disparities among countries, regions and socio-economic groups are increasing the pressure on both national and EU level authorities, leading to the conclusion that the current socio-economic systems have reached their limits. Thus, the social market economy (SME), "third path" which mixes the purely liberal market economy with the social economic model might be one viable solution. Historically, the model corresponds to the real economic policy of the German Federal Republic after the 1950s, thus it is sometimes called Rhine capitalism. Such a model might be both the solution for national-level European economies and for the entire Union and thus, for a successful implementation a two-step approach should be considered appropriate. Thereby, in the first stage an SME might be implemented at national level in as many as possible EU member states and in the second phase a SME might be created at the level of EU by aggregating the smaller national SMEs. Due to the fact that in a SME the weaker geographical regions and industries are encouraged so that "fair" distribution of wellbeing is reached, it is highly probable that such a socio-economic model might be the appropriate alternative to fuel a sustainable growth of the Romanian economy. Using county level data, from the National Institute of Statistics and from the National Office of the Trade Register, for the year 2015, and an aggregated index, we show that the Romanian economy is highly polarized with a few growth poles (islands) and a large number of underdeveloped units. Thus, it becomes obvious that these important disparities will hinder a future sustainable development and by consequence a clear "road-map" represented by the SME model might prove to be a viable solution for the Romanian economy.
\end{abstract}

Keywords: socioeconomic model, social market economy, economic development poles, regional disparities, economic development trends.

Please cite the article as follows: Strat, V.A. and Stefan, C. (2017), "The growth poles and the lagging regions of Romania - a county level approach for 2015", Management \& Marketing. Challenges for the Knowledge Society, Vol. 12, No. 3, pp. 456-473, DOI: 10.1515/mmcks-20170028.

\section{Introduction}

In the nowadays European socio-economic context it is obvious that the challenges sourced from the existence of severe disparities: between different economies, between different regions, between different socio-economic groups and ultimately between different citizens are increasing and piling the pressure on both European level authorities and national governments. Therefore, it is clear that the European policies designed for mitigating the regional and social disparities have reached their 
limits and in the current socio-economic models are almost useless. As a consequence, in order to ensure a sustainable development of the European construction it is crucial to develop and implement a new optimized socio-economic system with real leverage on diminishing and correcting these disparities. The implementation of the social market economy as envisaged by Muller Armak, and implemented in Germany and some northern European economies, might be the answer to this increasing pressure. In order to allow enough time for the adjustments to take place the implementation process might be a two-step approach, organized in a bottom-up fashion. In the first stage, the system might be adapted (so that it can successfully face the challenges raised by the common European market) and implemented at national level in as many EU member states as possible. Consequently, the system would be constructed at EU level like a puzzle by mixing individual pieces which belong to the same greater construction. Thus, the social market economy, which mainly tries (and, as seen in some economies, succeeds) to ensure that the right balance is maintained between the economic players, by correcting or eliminating market failures that might arise on the liberal market, looks like being an option that should be considered for further investigation both by practitioners (authorities and private economic players) as well as scholars.

As already stated, the two-step approach should be constructed starting from the national level and the new EU members, such as Romania, can be considered ideal candidates for the implementation of the model since its market economy, built on the wreckages of the former communist, over-regulated and centralized model, has clearly reached its limits and has failed to position the country on a path of sustainable development. The failure of the model is visible both internally where regional disparities are significant and the economic development is highly polarized as well as at the external level where, due to the "unfair" distribution of prosperity, the labor force is migrating towards the developed west and consequently, the national economy is generally lagging, in the broader European context.

In order to provide some clear evidence of the severe regional level disparities we use data on eight main socio-economic indicators (at county level) and visually present their distribution at the level of the country, using tables, maps and histograms. Moreover, we take one step further in identifying both the growth poles and the lagging regions by a comparative analysis of the Romanian counties using an aggregate index (constructed from eight individual variables). Therefore, we try to take a first step in the broader proposal of developing a new economic system, by mapping the current situation on a multi-criterial level.

The paper includes a section where the general framework and a brief review of the literature is presented, a short section where the methodological approach is described and a section where the main findings are presented. These sections are accompanied by some introductory and conclusive remarks.

\section{General framework and literature review}

The economic development of a nation and the standard of living of the citizens is strongly influenced in the nowadays reality by the socio-economic model of the country. Also of significant importance in the contemporary reality, where the 
national economies are integrated in a larger global system, are the sustainability and the diversification of an economy. Both these characteristics are the ones which can ensure the resilience of an economy in periods of crises and when external shocks severely affect one or several economic sectors.

Most of the economies of the present are organized around three main models covering the entire spectrum from the right side capitalism to the left side socialism. At their confluence, considered by some scholars and practitioners as being an "optimal mix" there is the Rhine capitalism (as presented among others by Bakan and MacDonald, 2002). This socio-economic model, also known as the social market economy, is considered the foundation of the German economic model (Goldschmidt and Rauchenschwandtner, 2007; Spicka, 2007). Due to its characteristics it started to be applied in several other Northern European economies (Turner, 1998). Moreover, since a few years it also became the cornerstone of the socio-economic model of the EU.

The social market economy is structured so that it provides a fundamental role to the development of the free market which is envisaged as one of the prosperity engines. In the same time this socio-economic model considers that "fairness" (seen as equality of opportunities by Wheeler, 2002) between all participants to the economic game is the other engine that can ensure prosperity, providing sustainability to the economic development. Therefore, it becomes obvious that the socio-economic model of social market economy is not a third way but a middle way which uses tools influenced by the socialist, over-regulated system, in order to impose boundaries to the "free" capitalist development so as to diminish economic disparities between different actors of the economic game. By using a wide range of economic, fiscal and social instruments the social market economy tries to ensure a fair compensation for effort and by doing so it tries to reinforce the stability of an economy and the sustainability of its growth.

The success of this socio-economic model depends heavily, as two of its "fathers", Muller-Armack (1956) and Eucken (1932) have envisaged, by its capability to ensure the balance between free enterprise and social responsibility. The state's authority takes the leading role in the system of social market economy in setting the boundaries, designing and implementing the policies which can ensure the equality of opportunities and therefore ensure the success of the "middle way". Thus, the state is one of the key economic actors of this system without substituting the role of the free market, which still remains responsible for fuelling economic growth. As F.A. Hayek argued in 1939 and as several other authors have observed (Scharpf and Fritz, 2009) the latest evolution of the European Union (as it is designed today) does not seem to support the development of the social market economy, due to the fact that they promote the "weakening" of the national authorities, which, in the case of SME, represent the main catalyst and balance keeper. The main weak point of the general European framework is represented by the fact that the "weakening" of the national states is not replaced with an equally strong or stronger system of authority which can reduce the pressure on the social side of the model. More precisely, in the nowadays framework of the European Union, the common market and the migratory flows seem to be the most important elements destabilizing the European social 
market economies, by putting pressure on the social side of the model, diminishing its functionality and increasing the internal forces which determine individual states to leave the EU orbit.

Even though translating the model of social market economy from national level to the Union's level seems to be the greatest challenge of the present, one does not need to forget that the early stages of the EU, when national control over the level of economic integration was very strict, the states functioning in the SME system were reaching the peak of their economic development. Therefore, it is obvious that in those stages the EU was a factor with positive impact on the national social market economic systems. In the nowadays socio-economic context, the EU is supporting the economic growth of its members through the development of the common market and therefore can be considered an enhancer of the "capitalist" side of the national social market economies. At the same time, the free movement of population and labor force puts significant pressure on the social side of the strong social market economies and as a consequence it can be considered one of the factors with a high negative impact on the social market economic model.

Being therefore obvious that the current European framework is not prepared to support the development of the social market economy at the level of the entire Union, a new approach is required. As some stakeholders have argued, the structures of a "federal Europe" (Buchanan, 1995/96) might be the solution that can diminish the pressure exerted on the social systems of some strong Western social market economies. However, such a development direction at the level of the European Union does not seem realistic today, since consensus among EU members is difficult to reach. On the contrary, the weakening of the EU structures seems more plausible today when several scenarios are proposed (see the white paper presented by the President of the Commission on the $1^{\text {st }}$ of March 2017) for the future of the Union.

Since a top-down implementation of the social market economy at the level of the European Union does not seem to be a scenario with a high level of feasibility, an alternative one, with a bottom-up approach should be considered. Thus, a stepwise approach in at least two phases would be preferable. The first phase would involve creating functional national social market economies in as many as possible of the EU member states. The second phase would involve merging these national social market economies in a single EU-level system, which would be coordinated by EU level institutions in order to ensure similar approaches inside EU member states through their national counterparts. At the same time with the implementation of the first step of the process, the EU needs to work harder around the idea of "equilibrium" and reduction of disparities through an increased interconnectivity between the European entities. One of the first advantages of this stepwise approach would be represented by the emergence of natural incentives for the diminishing of the east-west and southnorth migratory flows, which at this moment increase the socio-economic disparities at the level of the Union, by concentrating the human capital and the labor resource in areas where they also increase the pressure on the social welfare systems, increasing the social turmoil. In the same time, these "uncontrollable" flows of human capital and labor force work against the main regional policies developed by the EU with the clear purpose of reducing the regional disparities. 
The reduction of disparities between regions should also be an important concern for the governments of the new member states of the European Union due to the fact that significant disparities were generated along the last 25 years. The process of replacing the communist highly centralized economies of the east with functional market economies has created inequalities which are clearly hindering the economic growth and the development of these states. For the case of Romania, the economic model that was developed after the fall of communism, namely the market economy which generated important disparities (Goschin et al., 2008) at county level and even regional level is clearly showing its limitations. One of the main failures of the Romanian system is represented by the low development of the transport infrastructure which is the clear cause of the low internal mobility of the labor force and heavily distorts the labor market, making it unfit to support a sustainable economic development of the entire national economy (from a spatial perspective). Moreover, this under-development of the transport infrastructure generates a very low attractiveness level for both Romanian and foreign capital. As a consequence, the widening of the internal regional disparities seems to be the natural outcome.

Another remarkable weak point of the socio-economic development model created in the last 26 years in Romania (Miron, 2010) is represented by the fact that it failed to mitigate fast enough the disparities between the Romanian economy and its Western counterparts and generated in this way large migratory outflows which have led to important disequilibria on the internal labor force market and also on other sectors (social security budgets).

Therefore, the need for a new socio-economic model for Romania seems obvious and might be the natural answer in mitigating both the internal regional disparities (Miron, 2009) and the disparities between the national economy and the Western ones. Internally, the identification of the growth poles and also of the lagging regions should be the first step of this process. Further, the second step should concentrate on increasing the connectivity measured through transport infrastructure between regions so that both capital and labor force can move to balance the supply and demand. Finally the third step should be represented by the implementation of the social market economy which can enhance the competitiveness of the entire Romanian economy and can also ensure regional stability in the south-eastern region of the European Union.

\section{Research goal, methodology and data issues}

The main goal of the present research paper is to quantitatively chart the development level of the Romanian national economy, at county level, so that both the growth poles and the lagging regions can become easily visible. Therefore, the research presented in this paper should be a potential answer for the first step in upgrading the socio-economic level of Romania.

Therefore, the research method we adopt in this paper is based on two main steps. First we analyze eight variables, which we consider to be indicative of the level of development in the different Romanian counties: i) number of firms, ii) number of employees, iii) salary, iv) urbanization, v) education, vi) culture, vii) tourism and viii) health. Variable i) represents the number of firms registered and active in a 
county. Variable ii) is the plain number of employees in each county. Variable iii) is defined by the average gross monthly salary in the Romanian currency RON. Variable iv) is the percentage of population living in urban areas out of the total population of a county. Variable v) counts the number of educational units, ranging from kindergarten to elementary school, middle school, high school, professional schools and collegelevel education. Variable vi) encompasses the number of artistic events, ranging from drama to animation, opera, musicals, philharmonic, popular orchestras and others. Variable vii) counts the number of tourists arriving in all sorts of touristic units such as hotels, hostels, motels, tourist villas, bungalows, camping and guest houses. Variable viii) represents the number of doctors employed in public health institutions in each county (we did not consider private institutions, because the numbers would have overlapped). We assume from the beginning that the variables will show a high degree of heterogeneity with respect to the separate counties and we are interested in mapping the regional disparities. Our data source is the Romanian National Institute of Statistics and the time span we selected is the year 2015. Initially, we looked at a larger interval between 2012 and 2015 but the variability between years was shown to be much smaller than the variability between counties and regions. We therefore decided to employ only the year 2015 as unique time point and we rejected the use of a panel econometric model. Each of the eight variables thus consists of 42 observations, corresponding to the 42 Romanian counties (where the city of Bucharest is considered to be a county itself). The dataset is complete, with the only exception of one missing observation for the variable Culture in the county of Calarasi (thus this variable contains only 41 observations).

Our primary method consists of descriptive statistics by employing numerical indicators and graphical representations of the distributions for the eight variables of interest. This helps us intuitively understand how the variables behave. In a further step, we run Pearson correlations to understand if there is any relationship between the variables. Finally, we design visual data maps which highlight the differences between counties with respect to the variables.

The second step involves aggregating these variables in a single indicator that can efficiently be used to identify both the growth poles, where the socio-economic activity is intense, and the lagging regions which are endangered by depopulation processes and increase of poverty. Since we consider both the reproducibility and the usability of the proposed methodology important, we consider that aggregating the eight variables in a single index, using equal weights is the appropriate approach. The method that we propose requires two stages:

1. We re-scale all variables, so that for each territorial unit we obtain a value between 0 and 1.

$$
z_{i t}=\frac{x_{i t}-\min U}{\max U-\min U}
$$

$\mathrm{x}_{\mathrm{it}}$ - the value of variable $\mathrm{x}$ for unit (i), for year $(\mathrm{t})$

minU - a value lower than the minimum for $x$ for all units (i)

maxU - a value higher than the maximum for $\mathrm{x}$ for all units (i) 
The usage of minU and maxU instead of min and max helps us obtain values larger than 0 and lower than 1 for each territorial unit, so that the interpretation of data is more intuitive.

2. We compute the value of the aggregated index as a simple average of the eight values of the used variables.

$$
\text { Index }=\sum_{j=1}^{8} \frac{1}{8} * z_{j}
$$

\section{Empirical results}

Descriptive Statistics

Table 1 presents descriptive statistics for the variables. It encompasses measures of the distributional center (mean, median), dispersion (standard deviation) and distortion of the normal distribution (skewness, kurtosis).

Table 1. Mean, median, standard deviation, skewness and kurtosis of the eight variables in 2015

\begin{tabular}{|l|r|r|r|r|r|r|r|r|}
\hline & $\begin{array}{c}\text { Number } \\
\text { of Firms }\end{array}$ & $\begin{array}{c}\text { Number of } \\
\text { Employees }\end{array}$ & Salary & $\begin{array}{c}\text { Urbaniz } \\
\text { ation }\end{array}$ & $\begin{array}{c}\text { Educ } \\
\text { ation }\end{array}$ & $\begin{array}{c}\text { Cultu } \\
\text { re }\end{array}$ & $\begin{array}{c}\text { Touris } \\
\text { m }\end{array}$ & Health \\
\hline Mean & 12234 & 109795 & 2235 & 0.4917 & 169 & 550 & 236235 & 832 \\
\hline Median & 8110 & 79320 & 2133 & 0.46 & 149 & 326 & 125687 & 416 \\
\hline Std. deviation & 16439 & 125838 & 366 & 0.1374 & 81 & 974 & 325282 & 1293 \\
\hline Skewness & 5.292 & 5.196 & 2.041 & 1.444 & 3.076 & 5.259 & 3.083 & 4.444 \\
\hline Kurtosis & 31.35 & 30.63 & 5.36 & 3.35 & 14.12 & 30.92 & 11.01 & 23.09 \\
\hline No. obs. & 42 & 42 & 42 & 42 & 42 & 41 & 42 & 42 \\
\hline
\end{tabular}

Source: Authors' own computations, based on data from the National Institute of Statistics, Romania.

We briefly describe the interplay of these statistical indicators. Whenever the median is smaller than the mean, such is the case for all variables in Table 1 , the interpretation is that the variables are highly polarized across counties, with many regions having a low level of the development (driving down the median), and a few economic strongholds with very high level of development (which inflate the mean). The mean is easily influenced by the tails of the distribution: it becomes distorted by a few overdeveloped counties. Such is the case for variable i) the number of firms, where the average number of companies active in a county is of 12234 . However, the median value is much lower, at 8110 , indicating many counties with few or very few firms. Thus, the mean can only be analyzed correctly when it is accompanied by the median (insensitive to the distributional tails) and especially by the standard deviation. The standard deviation, relative to the mean, shows how spread out a distribution is from its mean and therefore a high level of deviation diminishes the reliability of the mean. The most severely influenced variables are the number of firms and employees, culture, tourism and health, where the standard deviation surpasses the value of the mean. Less spread out variables are salary, urbanization and education, where the mean is more meaningful and its difference to the median relatively smaller. 
Distortions of a distribution away from the normal distribution are also emphasized by positive levels of skewness and kurtosis. A distribution with positive skew has a fat tail towards its left side, showing again a large concentration of counties in regions with weaker economic activity. The positive value of kurtosis shows a pointy, or high, distribution (compared to the normal distribution), which reveals that there is a very large number of under-developed units. Again, as stated before, we find more extreme values of skewness and kurtosis for number of firms, employees, culture, tourism and health, while for the less extremely distributed variables salary, urbanization and education the skewness and kurtosis are much smaller.

From Table 1 we can conclude that we can group the variables into: A) a more distorted group (including variables i, ii, vi, vii and viii), in which the unequal development is more pregnant and B) a more normally distributed group (including variables iii, iv and v), where the differences are less stark. However, the most important result from Table 1 is that all eight variables follow a similar pattern: they all have means higher than the median and positive values for skewness and kurtosis.

All in all, it seems that the Romanian economy is highly polarized, with a few counties yielding the highest levels of industrialization, and most counties being left behind. The shapes of the distributions become much more visible and easier to understand in the next section.

\section{Distributions}

In this section we provide a visualization of the distributional shapes for five variables, which we selected out of the eight. The main criterion of selection was to exclude distributions that are strikingly similar to other distributions. As stated before, for all eight variables we find distributions with positive skewness and kurtosis, showing a clear polarization of the Romanian economy around a few growth poles (outliers) and a large number of under-developed counties.

The five variables for which we decided to show distributions are: i) number of firms; iii) salary; iv) urbanization; vi) culture and vii) tourism. They are depicted in Figures 1 to 5 . All figures were produced using the software package SPSS Statistics 17.0. The phenomenon of agglomeration of observations on the left side of each distribution, showing most counties to suffer of under-development is most striking in: number of firms (Figure 1), culture (Figure 4) and tourism (Figure 5), although somewhat milder in the latter variable. The general tendency for agglomeration is confirmed for the remaining variables salary (Figure 2) and urbanization (Figure 3), albeit to a lesser extent. A few over-developed counties distort the value of the mean since they perform very well. In each distribution we find the city of Bucharest as extreme outlier. It represents the particular case of uniquely high economic development according to all variables. In variable iv) urbanization Bucharest is the only region with a level of $100 \%$. For the variable vii) tourism there are two more outliers, the counties of Constanta and Brasov. 


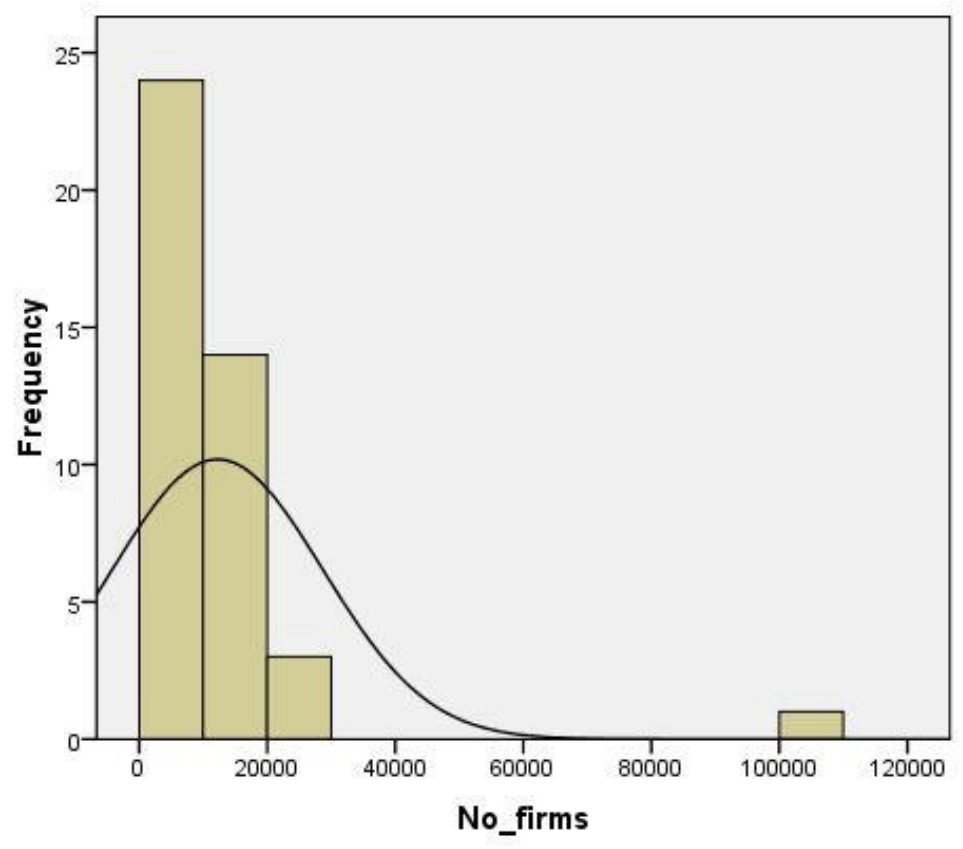

Figure 1. Distribution of number of firms, 2015

Source: Authors' own computations, based on data from the National Institute of Statistics, Romania.

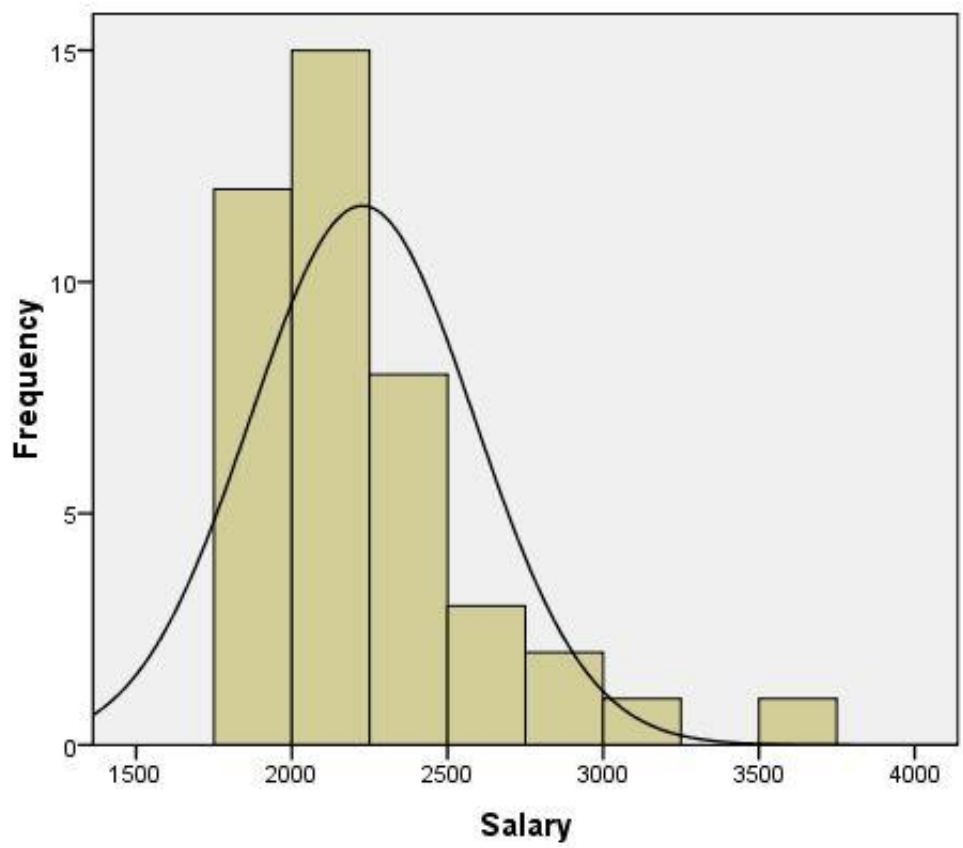

Figure 2. Distribution of salary, 2015

Source: Authors' own computations, based on data from the National Institute of Statistics, Romania. 


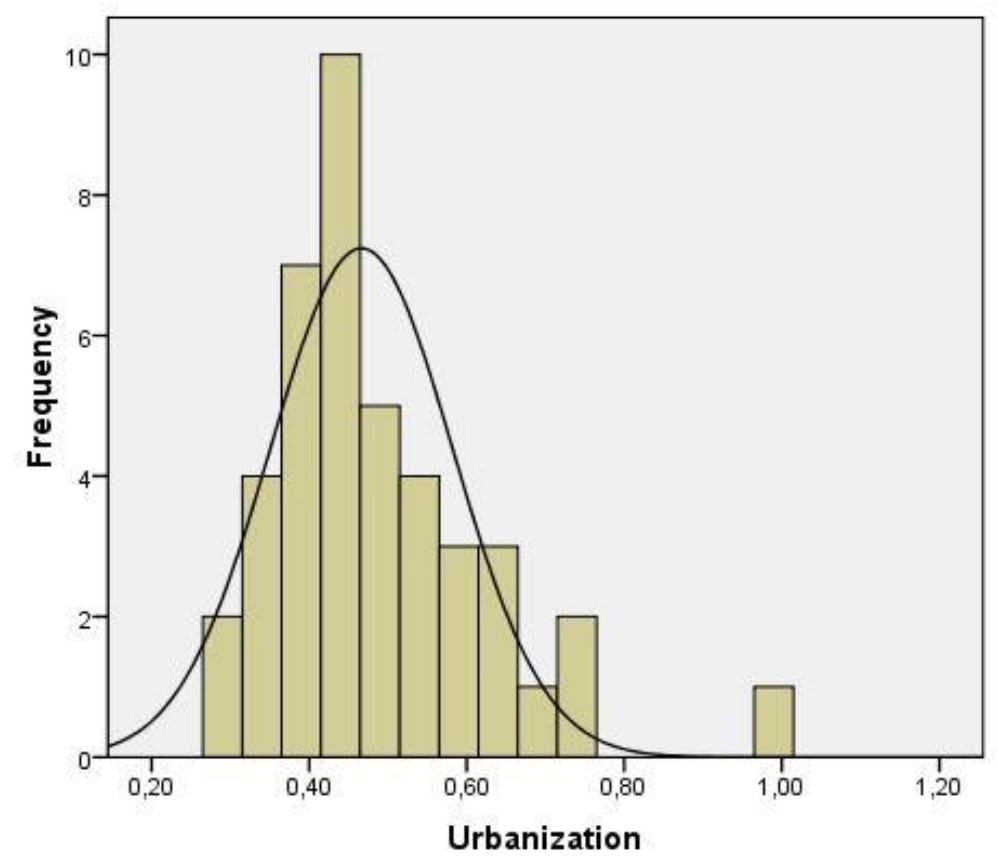

Figure 3. Distribution of urbanization, 2015

Source: Authors' own computations, based on data from the National Institute of Statistics, Romania.

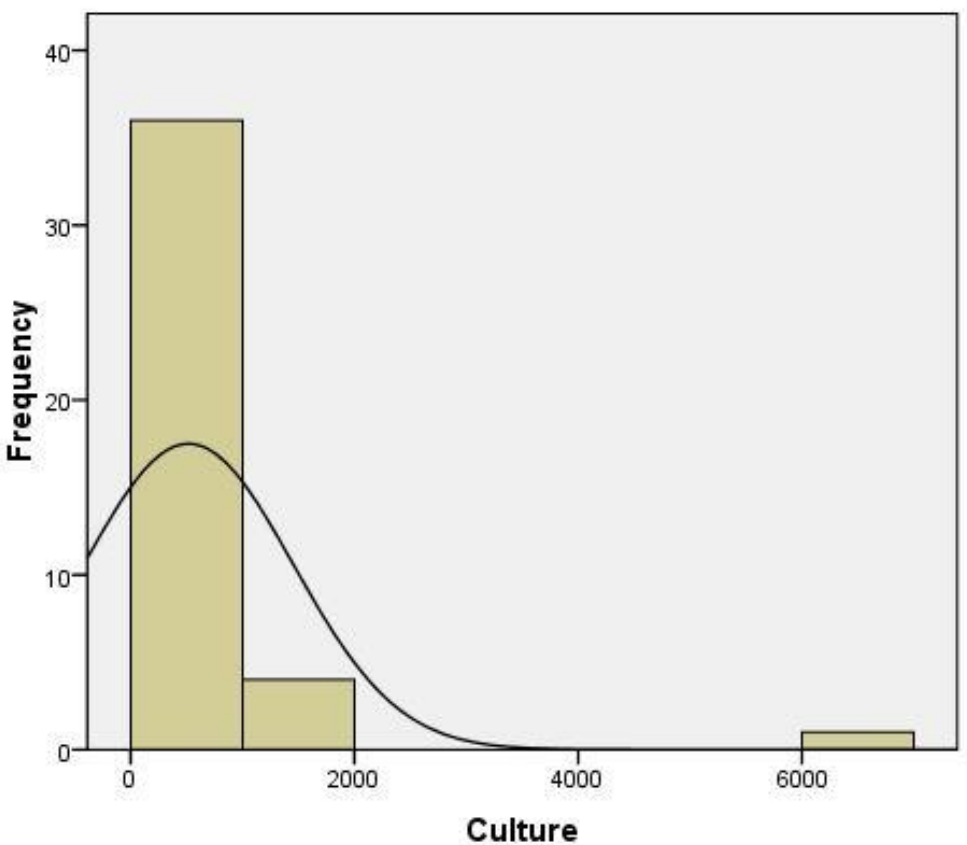

Figure 4. Distribution of culture, 2015

Source: Authors' own computations, based on data from the National Institute of Statistics, Romania. 


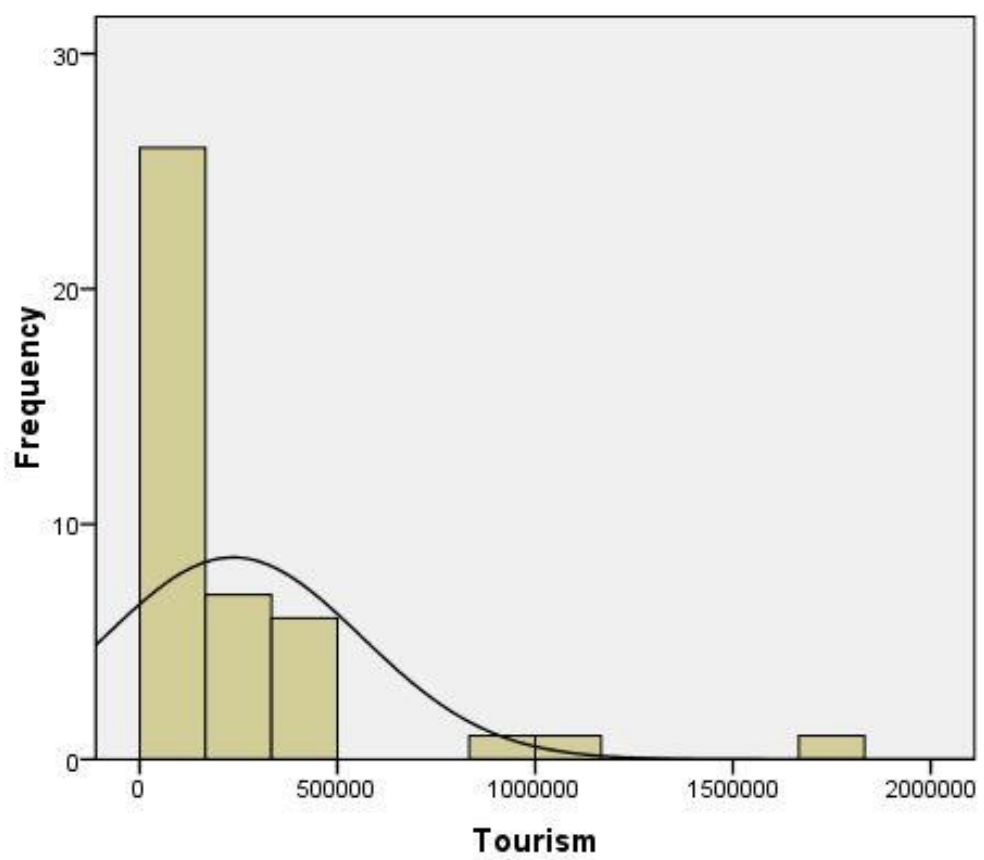

Figure 5. Distribution of tourism, 2015

Source: Authors' own computations, based on data from the National Institute of Statistics, Romania.

We did not include the distribution of variable ii) number of employees, because it has an almost identical shape to variable i) number of firms. Furthermore, variable v) education was particularly similar to iv) urbanization and thus the aforementioned was not included. The extremely skewed distribution of vi) culture highly resembled that of vii) health and therefore we only presented the first one.

This section shows a very stark contrast in development with respect to culture and health, followed by the number of economic agents (firms and employees) as well as tourism. Following the same tendency for agglomeration versus outliers, albeit in a less extreme fashion, we find salary, urbanization and education.

\section{Correlations}

In this section we run Pearson correlations between all eight variables. The correlation coefficients as well as their significance levels (2-tailed) and number of observations (N) are summarized in Table 2.

Results of Table 2 show very high degrees of multi-collinearity between nearly all variables. There is an extreme degree of interdependence between the number of firms and the number of employees (99.4\%), which should come as no surprise because firms need labor to sustain their activity. However, there is a surprisingly high degree of correlation between all other variables as well, and their unobjectionable significance levels (all at the 0.01 threshold) show that these variables follow a very similar path and are influenced by the same underlying mechanism, namely the polarization of the Romanian economy and society. The correlation coefficients range from very high (above 0.9) to high $(0.7$ to 0.9$)$ and medium-large, with the lowest value at 0.599 , which is the correlation between salary 
and urbanization. Interestingly, the correlations between urbanization and the other variables indicate that the Romanian economy seems to be more active in cities and less active in rural areas.

Table 2. Pearson correlations between the eight variables in 2015

\begin{tabular}{|c|c|c|c|c|c|c|c|c|}
\hline & & $\begin{array}{l}\text { No. of } \\
\text { Employee } \\
\text { S }\end{array}$ & Salary & $\begin{array}{l}\text { Urbaniz } \\
\text { ation }\end{array}$ & $\begin{array}{l}\text { Educati } \\
\text { on }\end{array}$ & Culture & Tourism & Health \\
\hline $\begin{array}{l}\text { No. of } \\
\text { Firms }\end{array}$ & $\begin{array}{l}\text { Corr. } \\
\text { Sig. } \\
\text { N }\end{array}$ & $\begin{array}{l}0.994^{* *} \\
0.000 \\
42\end{array}$ & $\begin{array}{l}0.789^{* *} \\
0.000 \\
42\end{array}$ & $\begin{array}{l}0.701^{* *} \\
0.000 \\
42\end{array}$ & $\begin{array}{l}0.911^{* *} \\
0.000 \\
42\end{array}$ & $\begin{array}{l}0.949^{* *} \\
0.000 \\
41\end{array}$ & $\begin{array}{l}0.841^{* *} \\
0.000 \\
42\end{array}$ & $\begin{array}{l}0.947^{* *} \\
0.000 \\
42\end{array}$ \\
\hline $\begin{array}{l}\text { No. of } \\
\text { Emplo } \\
\text { yees }\end{array}$ & $\begin{array}{l}\text { Corr. } \\
\text { Sig. } \\
\text { N }\end{array}$ & & $\begin{array}{l}0.781^{* *} \\
0.000 \\
42\end{array}$ & $\begin{array}{l}0.728^{* *} \\
0.000 \\
42\end{array}$ & $\begin{array}{l}0.922^{* *} \\
0.000 \\
42\end{array}$ & $\begin{array}{l}0.953^{* *} \\
0.000 \\
41\end{array}$ & $\begin{array}{l}0.851^{* *} \\
0.000 \\
42\end{array}$ & $\begin{array}{l}0.951^{* *} \\
0.000 \\
42\end{array}$ \\
\hline Salary & $\begin{array}{l}\text { Corr. } \\
\text { Sig. } \\
\text { N } \\
\end{array}$ & & & $\begin{array}{l}0.599^{* *} \\
0.000 \\
42 \\
\end{array}$ & $\begin{array}{l}0.719^{* *} \\
0.000 \\
42\end{array}$ & $\begin{array}{l}0.681^{* *} \\
0.000 \\
41\end{array}$ & $\begin{array}{l}0.661^{* *} \\
0.000 \\
42\end{array}$ & $\begin{array}{l}0.745^{* *} \\
0.000 \\
42 \\
\end{array}$ \\
\hline $\begin{array}{l}\text { Urbani } \\
\text { zation }\end{array}$ & $\begin{array}{l}\text { Corr. } \\
\text { Sig. } \\
\text { N }\end{array}$ & & & & $\begin{array}{l}0.642^{* *} \\
0.000 \\
42\end{array}$ & $\begin{array}{l}0.688^{* *} \\
0.000 \\
41\end{array}$ & $\begin{array}{l}0.768^{* *} \\
0.000 \\
42\end{array}$ & $\begin{array}{l}0.688^{* *} \\
0.000 \\
42\end{array}$ \\
\hline $\begin{array}{l}\text { Educat } \\
\text { ion }\end{array}$ & $\begin{array}{l}\text { Corr. } \\
\text { Sig. } \\
\text { N }\end{array}$ & & & & & $\begin{array}{l}0.846^{* *} \\
0.000 \\
41\end{array}$ & $\begin{array}{l}0.831^{* *} \\
0.000 \\
42\end{array}$ & $\begin{array}{l}0.907^{* *} \\
0.000 \\
42\end{array}$ \\
\hline $\begin{array}{l}\text { Cultur } \\
e\end{array}$ & $\begin{array}{l}\text { Corr. } \\
\text { Sig. } \\
\text { N }\end{array}$ & & & & & & $\begin{array}{l}0.816^{* *} \\
0.000 \\
42\end{array}$ & $\begin{array}{l}0.935^{* *} \\
0.000 \\
42\end{array}$ \\
\hline $\begin{array}{l}\text { Touris } \\
\text { m }\end{array}$ & $\begin{array}{l}\text { Corr. } \\
\text { Sig. } \\
\text { N }\end{array}$ & & & & & & & $\begin{array}{l}0.774^{* *} \\
0.000 \\
42\end{array}$ \\
\hline
\end{tabular}

Source: Authors' own computations, based on data from the National Institute of Statistics, Romania.

\section{Data map of counties}

To explain the variance between counties with respect to the variables, we designed visual data maps which depict the level of development in each county. The five variables we selected are the same as in the section "Distributions": i) number of firms; iii) salary; iv) urbanization; vi) culture and vii) tourism. Again, we selected these due to the fact that they showed more variability, while the depictions of the remaining three variables would have been redundant. Appendix 1 provides the full names of the counties, whose abbreviations are used in the data maps.

Figures 6-10 provide strong support for our thesis: there are a few centers driving up the Romanian economy, and a large number of counties left behind. This is mostly visible in Figures 6 and 10, where the contrast is the starkest. According to Figure 6, the number of firms is at a record height in Bucharest, followed at large distance by Cluj, Constanta and Timis. In the next cluster we find the counties of Arges, Dolj, Brasov, Iasi, Ilfov and Prahova. The remaining counties have a weaker level of development. A data map for number of employees, which we studied separately and do not include here, revealed the same pattern. The polarization is less pronounced in Figures 7 and 8, corresponding to salary and urbanization. These figures correspond 
to the less extreme distributions we have encountered in Figures 2 and 3. Especially for urbanization the between-county differences seem to be more leveled out. With respect to salary we find the county of Sibiu to have a good level of development. Still, even in these figures many counties are still under-represented. Besides, the level of urbanization is a weaker indicator of the level of economic development than the previous three variables. Figures 9 and 10 mark a return to disequilibrium by showing vast differences between the few strong counties and the many weak ones. For variable culture, we find Bucharest to be again the strong leader, followed at a distance by Brasov, Cluj, Valcea and Dolj. This result is more striking for tourism, where Bucharest is only followed by Brasov and Constanta (counties with geographic advantages), while the remaining counties are severely under-developed. All in all, the data maps show strong quantitative support for our thesis.

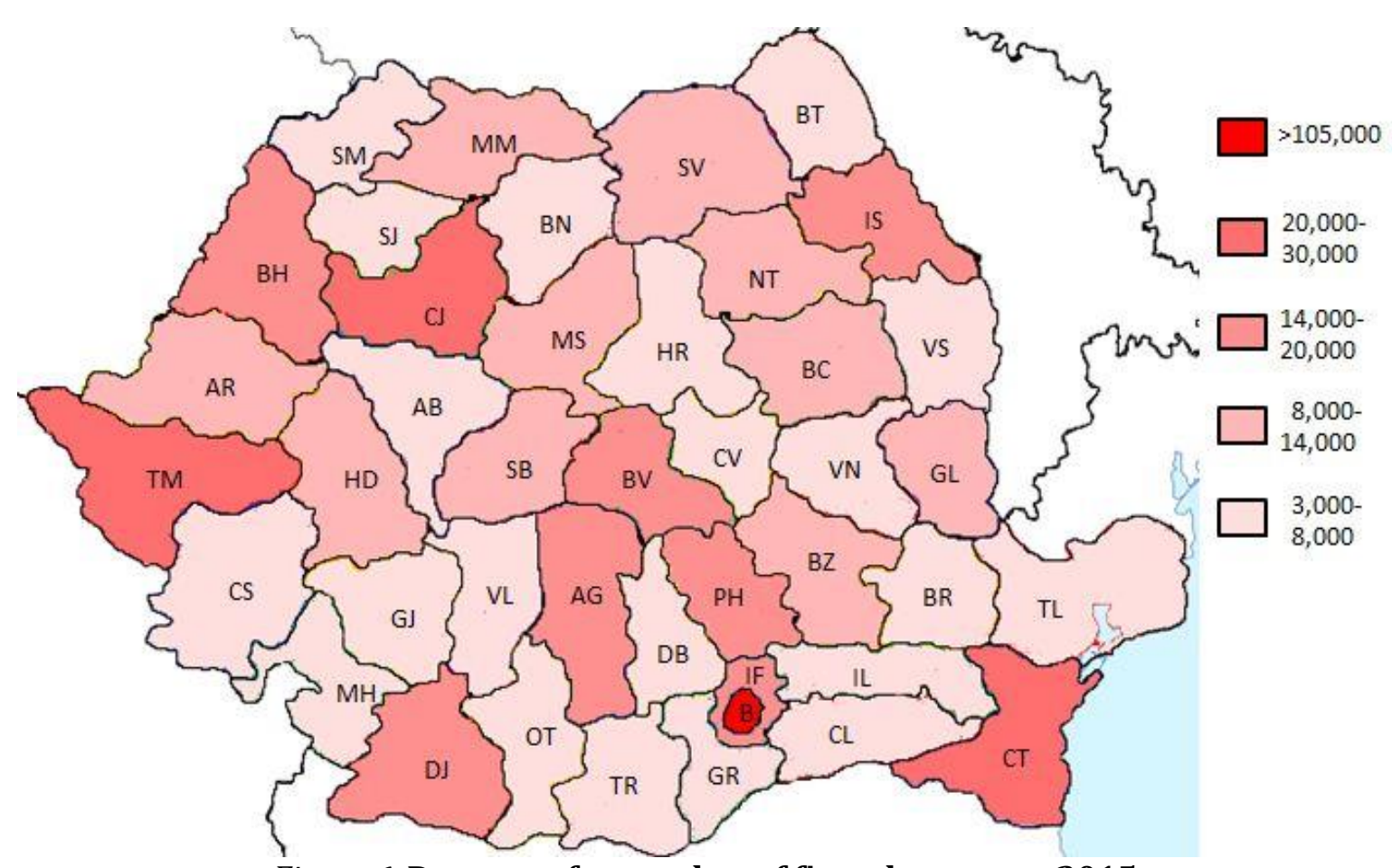

Figure 6. Data map for number of firms by county, 2015

Source: Authors' own graphics, based on data from the National Institute of Statistics, Romania. 


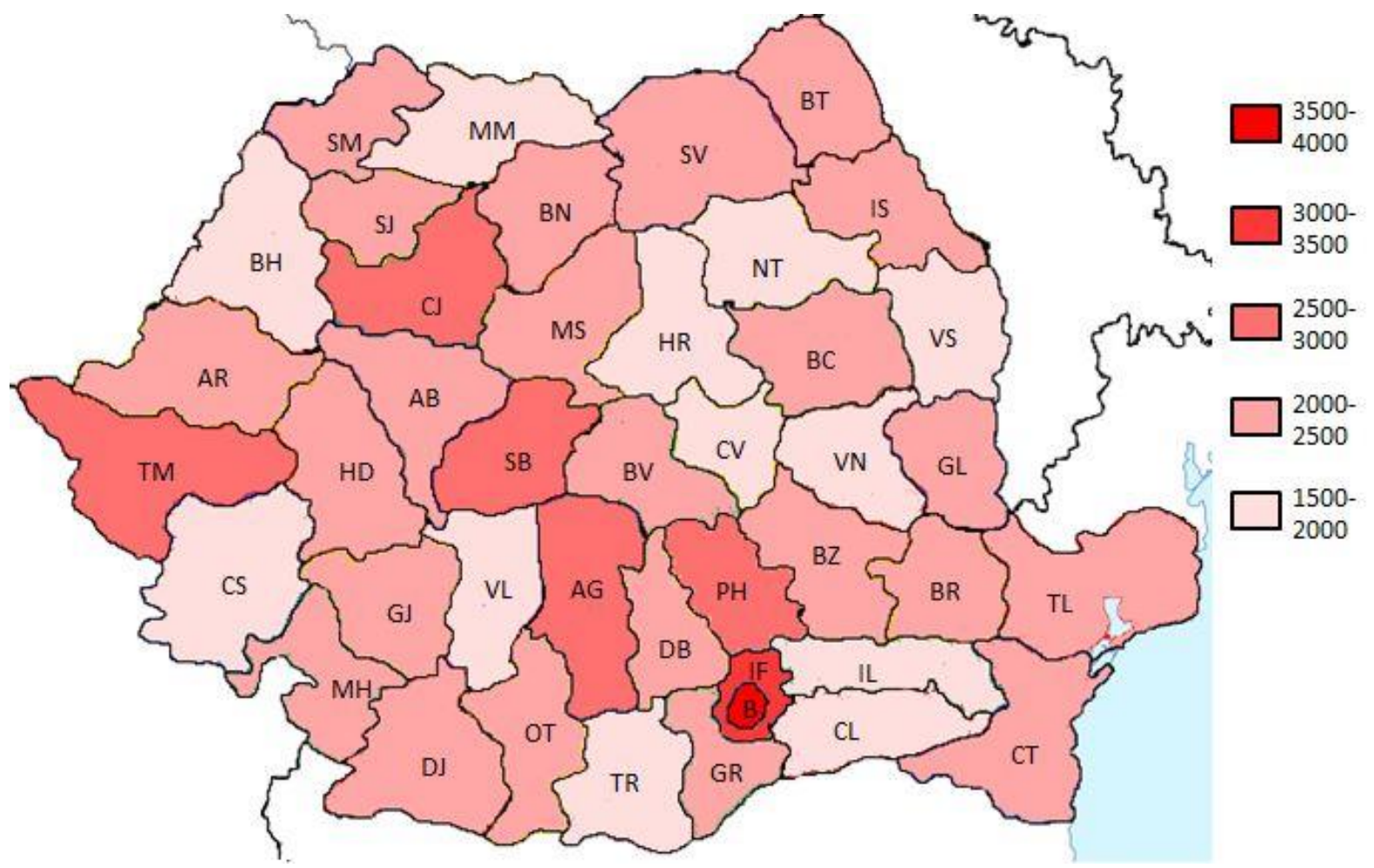

Figure 7. Data map for salary (RON) by county, 2015

Source: Authors' own graphics, based on data from the National Institute of Statistics, Romania.

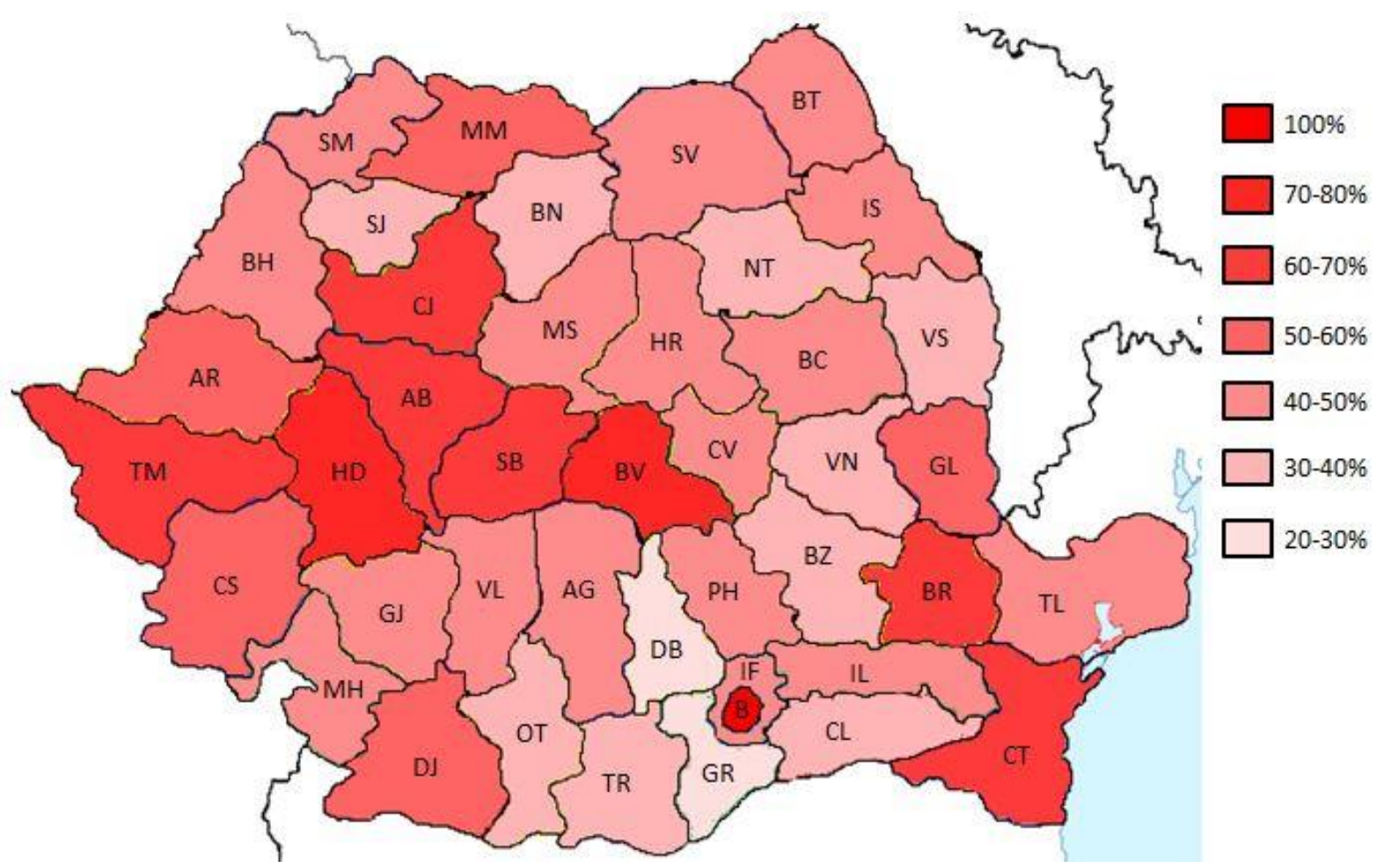

Figure 8. Data map for degree of urbanization (\%) by county, 2015

Source: Authors' own graphics, based on data from the National Institute of Statistics, Romania. 


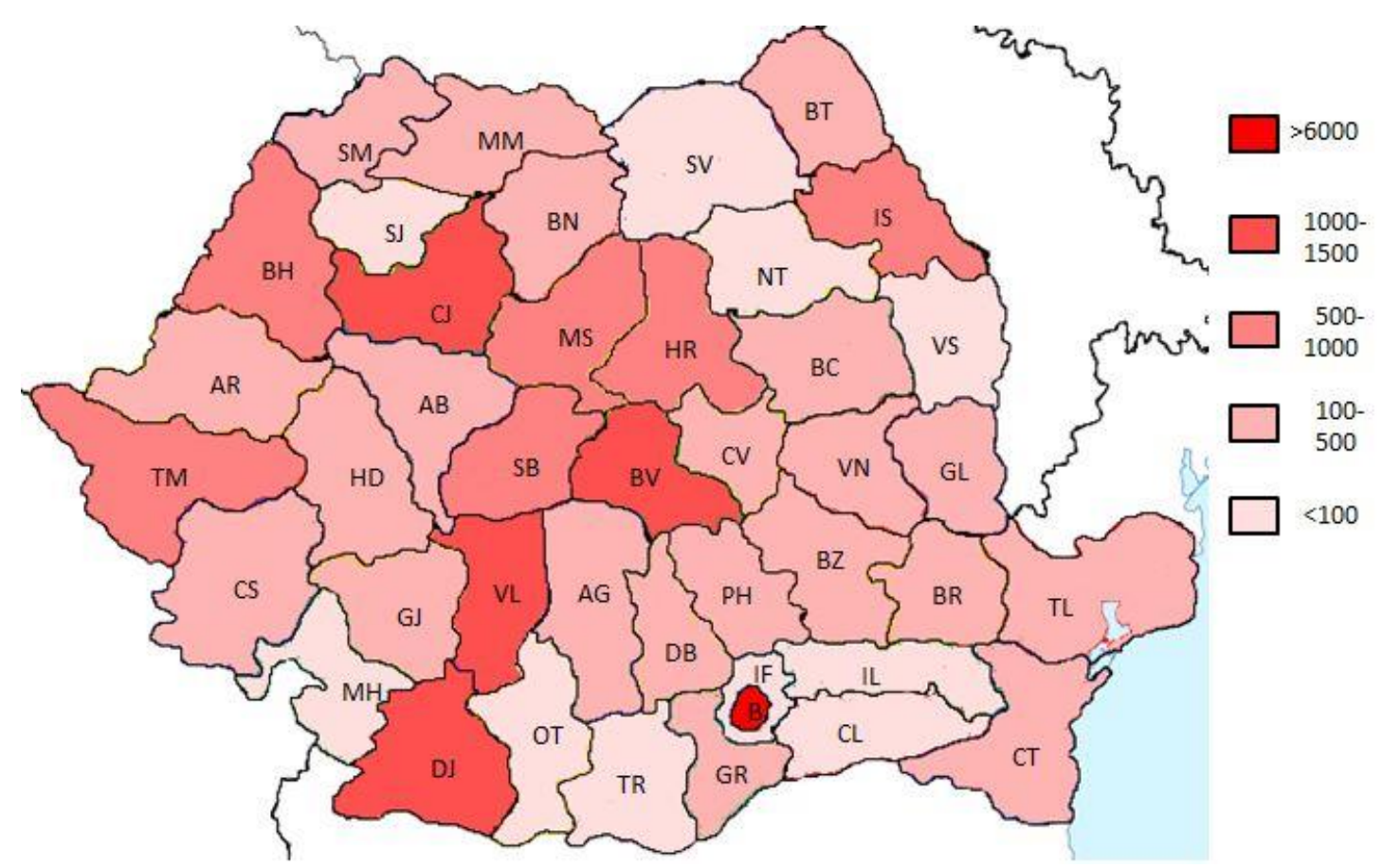

Figure 9. Data map for culture (no. of events) by county, 2015

Source: Authors' own graphics, based on data from the National Institute of Statistics, Romania.

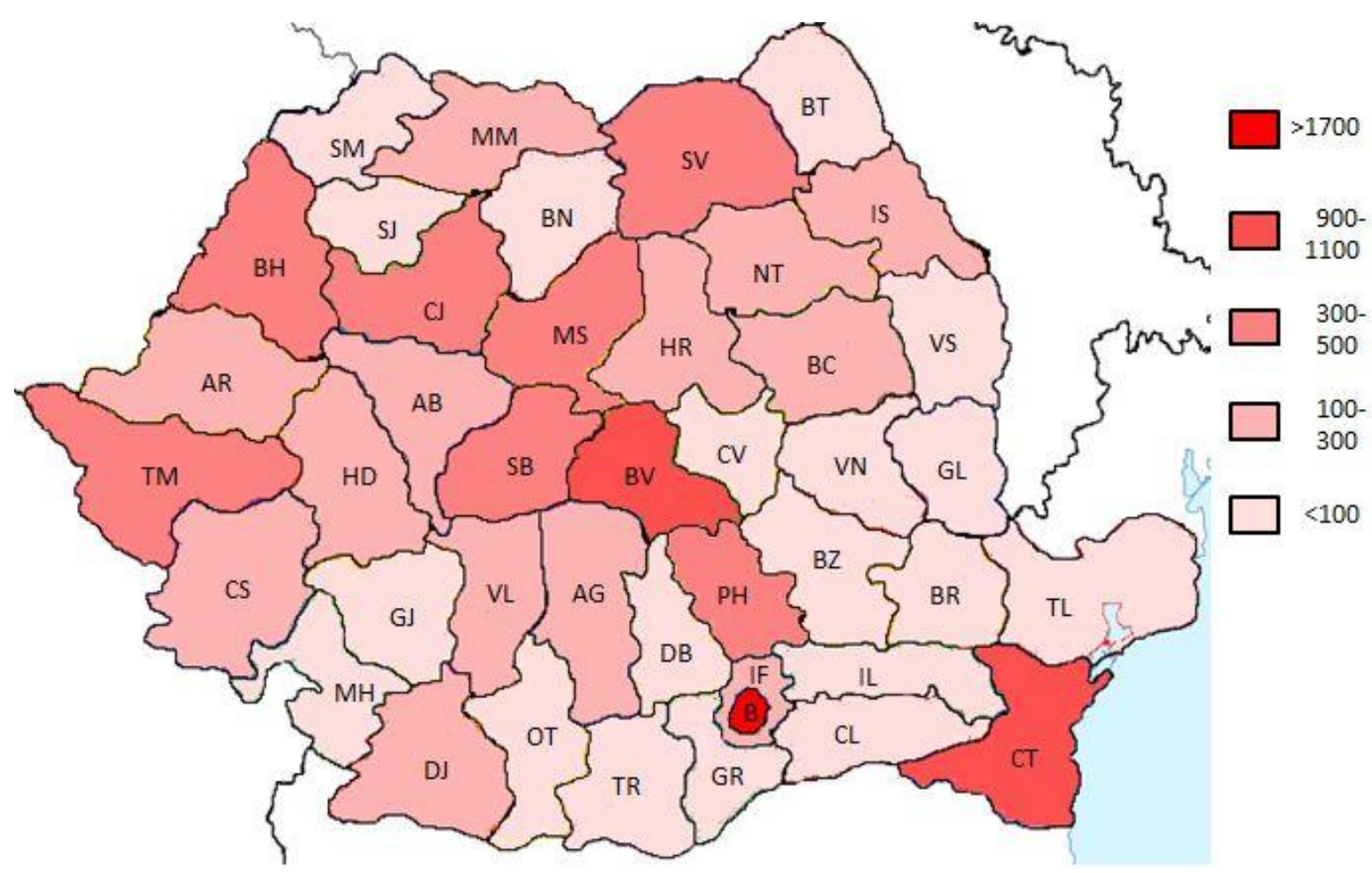

Figure 10. Data map for tourism (thousands of guests) by county, 2015

Source: Authors' own graphics, based on data from the National Institute of Statistics, Romania. 


\section{Aggregated index}

In the chapter describing the methodology we mentioned a second step of analysis through the construction of an aggregated index for each county. Using each value $\mathrm{x}_{\mathrm{it}}$, where $\mathrm{i}=$ county and $\mathrm{t}=2015$, we built the standardized values $\mathrm{z}_{\mathrm{it}}$ based on the formula described in the methodological chapter:

$$
z_{i t}=\frac{x_{i t}-\min U}{\max U-\min U}
$$

For instance, for the variable i) number of firms, we computed the minimum and maximum (which were 3260 and 109455) and rounded them down or up to compute minU and maxU (here, they were 3000 and 110000). To offer an example of the computational process, for the county Prahova $x_{i t}$ was equal to 16239 and the corresponding $\mathrm{z}_{\mathrm{it}}$ became 0.1237 . We then ran simple averages of the standardized values $\mathrm{Z}_{\mathrm{it}}$ for each county (all counties had 8 observations, except Calarasi who had only 7) and processed the final indices, which were sorted in descending order for each county and shown in Table 3. As mentioned before, the full names of the counties can be found in Appendix 1.

Table 3. Aggregated performance indices, sorted for all counties, 2015

\begin{tabular}{|l|l|l|l|l|l|l|c|}
\hline County & \multicolumn{1}{|c|}{ Index } & County & \multicolumn{1}{|c|}{ Index } & County & Index & County & Index \\
\hline B & 0.9957 & IF & 0.1695 & BR & 0.0994 & CV & 0.0622 \\
\hline CJ & 0.3259 & BH & 0.1684 & CS & 0.0894 & BN & 0.0617 \\
\hline BV & 0.2977 & AR & 0.1512 & SM & 0.0869 & VS & 0.0573 \\
\hline TM & 0.2900 & HD & 0.1486 & OT & 0.0861 & VN & 0.0538 \\
\hline CT & 0.2850 & GL & 0.1455 & HR & 0.0792 & SJ & 0.0520 \\
\hline IS & 0.2191 & AB & 0.1242 & BZ & 0.0759 & IL & 0.0501 \\
\hline SB & 0.2162 & MM & 0.1238 & DB & 0.0704 & TR & 0.0444 \\
\hline PH & 0.2061 & SV & 0.1233 & TL & 0.0698 & CL & 0.0398 \\
\hline MS & 0.1980 & BC & 0.1210 & MH & 0.0697 & GR & 0.0312 \\
\hline DJ & 0.1847 & GJ & 0.1101 & NT & 0.0668 & & \\
\hline AG & 0.1796 & VL & 0.1087 & BT & 0.0663 & & \\
\hline
\end{tabular}

Source: Authors' own computations, based on data from the National Institute of Statistics, Romania.

Table 3 shows Bucharest's status as "superstar" county, followed at a distance by the counties of Cluj, Brasov, Timis, Constanta, Iasi, Sibiu and Prahova. Indeed, these regions are the growth poles and strongholds of the Romanian economy and society. Naturally, Bucharest's index of more than 0.99 is biased by the fact that Bucharest achieves the maximum value for each variable. The next score is obtained by Cluj, at about 0.33 . There are 14 counties with scores between 0.1 and 0.2 , which may be seen as "middle ground". A large majority of 20 counties is lagging, with scores lower than 0.1 . The least developed counties are Teleorman, Calarasi and Giurgiu.

\section{Conclusion}

This paper should be regarded as an attempt to shed light on the importance of regional disparities and their potentially corrosive effect on the fabric of economies 
and societies. Our analysis is limited to the national level in Romania, however it raises questions about structural disequilibrium which are relevant at EU-wide level. Our quantitative evidence supports the need for resetting the socio-economic model adopted after the fall of communism by Romania, since it supported the creation of high economic discrepancies between regions and in no way can it ensure a sustainable future development.

A limitation of our analysis may consist in the choice of the eight variables. We selected four economic indicators (number of firms and employees, salary and tourism) and four social indicators (urbanization, education, culture and health) following the underlying logic of obtaining an appropriate composite for the socioeconomic development of regions. Still, the relevance and potential bias of the individual indicators can be scrutinized. Another limitation is that our paper is static, it does not investigate the evolution of the four variables over a longer period of time. As stated before, our primary focus was on inter-county variation and not on time variability. We leave the possibility of a panel econometric analysis to future research.

The main result of our quantitative analysis is to confirm a strong polarization of the Romanian economy, at county level, with a "superstar" phenomenon (the status of Bucharest city), a few very strong development poles (most notably Cluj, Brasov, Timis, Constanta and Iasi) and a large number of lagging counties. The aggregate index brings strong proof for the polarization effect. Another notable aspect is the fact that the degree of urbanization is positively correlated with the other variables, showing clearly that the rural areas were left behind by the current socio-economic model. The under-development of transport infrastructure in Romania contributed to this result.

The degree of regional disequilibrium shown in this paper should raise an alarm towards the reduction of disparities as essential goal of socio-economic policy. In Romania, the disparities were generated by following a too liberal approach and ignoring the middle way. We believe that the same tendency can also be observed at EU-wide level. The present paper achieved one important first step: to identify growth poles as well as lagging regions, therefore to present a mirror of the socio-economic development. It will be up to policy makers to mitigate regional disparities and increase competitiveness. They have at their disposal a powerful instrument which has proven its resilience over the decades, in the form of the social market economy.

\section{References}

Bakan A.B., MacDonald. E. (2002). Critical Political Studies: Debates and Dialogues from the Left. McGill-Queen's Press. pp. 69-70. ISBN 978-0-7735-6956-0.

Buchanan, J.M. (1995/96). Federalism and Individual Sovereignty. Cato Journal, Vol. 15, No. 2-3, pp. 259-268.

Eucken, W. (1932). Staatliche Strukturwandlungen und die Krisis des Kapitalismus, Weltwirtschaftliches Archiv, Vol. 36, No. 2, pp. 297-323.

Goldschmidt, N., Rauchenschwandtner, H. (2007). The Philosophy of Social Market Economy: Michel Foucault's Analysis of Ordoliberalism. Universität Freiburg, Freiburger Diskussionspapiere zur Ordnungsökonomik. 
Goschin, Z., Constantin, D.L., Roman, M., Ileanu, B. (2008). The current state and the dynamics of regional disparities in Romania, Romanian Journal of Regional Science, Vol. 2, No. 2, Winter, pp. 80-105.

Hayek, F.A. (1948/1939). The Economic Conditions of Interstate Federalism in: Friedrich A. Hayek, Individualism and Economic Order. Chicago: University of Chicago Press, pp. 255-272. (Reprinted from the New Commonwealth Quarterly Vol. 5, No. 2, 1939, pp.131-149).

Miron, D., Dima, A.M. and Vasilache, S. (2009). Indexes of regional economic growth in post accession Romania, Romanian Journal of Economic Forecasting, Vol. 11, No. 3/2009, pp. $138-152$.

Miron, D., Dima, A.M. and Vasilache, S. (2010). Models of The Intra-Regional Trade Influence On Economic Sustainable Development In Romania, Amfiteatru Economic, Vol. 12, No. 27/2010, pp. 27-35.

Müller-Armack, A. (1956). Soziale Marktwirtschaft - Handwörterbuch der Sozialwissenschaften, Vol. 9, Göttingen.

Scharpf, F.W. (1988) The Joint-Decision Trap: Lessons from German Federalism and European Integration. Public Administration. Vol. 66, No. 3, pp. 239-278.

Spicka, M.E. (2007), Selling the Economic Miracle: Economic Reconstruction and Politics in West Germany, 1949-1957, Berghahn Books.

Turner, L. (1998). Fighting for Partnership: Labor and Politics in Unified Germany. New York: Cornell University Press.

Wheeler, S. (2002). Corporations and the Third Way. Oxford: Hart Publishing.

\section{Appendix 1}

\begin{tabular}{|l|l|l|l|l|l|l|l|}
\hline \multicolumn{1}{|c|}{ County } & \multicolumn{1}{c|}{ Abr. } & \multicolumn{1}{c|}{ County } & Abr. & \multicolumn{1}{c|}{ County } & Abr. & \multicolumn{1}{c|}{ County } & Abr. \\
\hline Alba & AB & Cluj & CJ & Harghita & HR & Salaj & SJ \\
\hline Arges & AG & Calarasi & CL & Ilfov & IF & Satu Mare & SM \\
\hline Arad & AR & Caras-Severin & CS & Ialomita & IL & Suceava & SV \\
\hline Bucuresti & B & Constanta & CT & Iasi & IS & Tulcea & TL \\
\hline Bacau & BC & Covasna & CV & Mehedinti & MH & Timis & TM \\
\hline Bihor & BH & Dambovita & DB & Maramures & MM & Teleorman & TR \\
\hline Bistrita-Nasaud & BN & Dolj & DJ & Mures & MS & Valcea & VL \\
\hline Braila & BR & Gorj & GJ & Neamt & NT & Vrancea & VN \\
\hline Botosani & BT & Galati & GL & Olt & OT & Vaslui & VS \\
\hline Brasov & BV & Giurgiu & GR & Prahova & PH & & \\
\hline Buzau & BZ & Hunedoara & HD & Sibiu & SB & & \\
\hline
\end{tabular}

